\title{
Sexual behaviour of young and middle aged men in England and Wales
}

\author{
David Forman, Clair Chilvers
}

\begin{abstract}
Establishing patterns of sexual behaviour is essential in predicting the future spread of HIV. The sexual behaviour patterns of a randomly selected sample of 480 white men aged 15 to 49 were obtained by interview and analysed in relation to age, social class, and area of residence. Over half of the men had first had intercourse before the age of 18 and over three quarters had done so before the age of 20 . Age at first intercourse tended to be lower in more recent birth cohorts and in social classes III, IV, and V. Men in earlier birth cohorts tended to have had fewer heterosexual partners, both regular and casual, than those born more recently, but there were no social class or regional differences in the number of partners. Eight of the 480 men $(1.7 \%, 95 \%$ confidence interval 1.1 to $2.3 \%$ ) stated that they had had homosexual intercourse, four of whom had had one casual homosexual partner. Only one man had had more than $\mathbf{2 5}$ homosexual partners. The number of men having had homosexual intercourse was lower than is widely thought.

When possible, data were checked with national data or other surveys and thought to be accurate. The difficulties in collecting data of this nature are discussed.
\end{abstract}

\section{Introduction}

There is currently considerable interest in understanding patterns of sexual behaviour in the British population. Such information is mainly required to help to predict the future spread of transmission of HIV and correctly to target populations for educational information about AIDS. Several recent reviews have highlighted both the importance of such data in modelling the progression of AIDS and, in contrast, the shortage of available information. ${ }^{12}$

As part of a national population based case-control study of testicular cancer we interviewed several hundred young and middle aged men about a variety of possible risk factors, including sexual behaviour. This study will be reported in full in due course. In view of the urgency engendered by the AIDS epidemic, however, we present here some of the data on the first 480 men to be interviewed as controls in this study. Besides looking at reported sexual behaviour in this group of men we also considered factors such as the incidence of sexually transmitted disease, problems of infertility, and rates of vasectomy, which have rarely been studied in population samples.

\section{Subjects and methods}

The study took place within eight of the health regions in England and Wales. All men aged 15-49 living in specified districts in these regions in whom testicular cancer was diagnosed for the first time in 1984-6 were initially included in the study. For each index patient a control was randomly selected from the list of the general practitioner with whom the index patient was registered at the time of diagnosis. The controls were individually matched with the index patients for age (to within one year). Index patients and controls were excluded from the study if they were non-white or mentally unable to participate in the interview.

Each control with the consent of his general practitioner was informed in writing of the purpose of the study. The men were told that they would be interviewed about a wide range of topics, but sexual behaviour was not specifically mentioned. Strenuous efforts were made to follow up men selected as controls to obtain the maximum possible rate of response. If they failed to reply within three weeks they were telephoned or visited at home by the interviewing staff. Failure was accepted only if a man was totally untraceable, had moved away from the study area, or returned the reply form stating that he did not want to take part. In these instances another control was selected from the relevant general practitioner's list.

Interviews with controls took place during 1984-7, usually in general practitioners' surgeries but occasionally at the man's home or place of work. Interviews usually took $60-90$ minutes to complete with the questions on sexual behaviour coming after about 45 minutes. All data reported were for interviews that were carried out by women with no other person present.

For some analyses respondents were categorised by age at interview (15-19, 20-29, 30-39, 40-49), social class (I and II, III, IV and V), and area of residence (south and midlands, north and Wales). These regions were combined because of the broadly comparable social class structure among the respondents in the individual groups. Grouping was necessary because of small numbers in some categories. To analyse trends among groups in age at first intercourse log rank tests ${ }^{3}$ and Cox regression analyses ${ }^{4}$ were carried out. Elsewhere standard multiple regression techniques were used.

\section{Results}

\section{RESPONSE RATE}

Six hundred and two men were selected for interview, of whom 25 were found to have moved out of the study area. The remaining 577 were eligible for interview: 10 were not approached on the advice of their general practitioner, 56 refused to be interviewed, 20 could not be traced, and 11 consented to be interviewed only in the presence of their spouse or partner. The overall rate of response with no other person present $(480 / 577)$ was therefore $83 \cdot 2 \%$.

\section{COMPOSITION OF CONTROL POPULATION}

Table I shows the age, place of residence, social class, and marital state of the 480 men. The age
Forman.

Br Med $\mathcal{F}$ 1989;298:1137-42 
distribution reflected that of testicular cancer, which peaks between 25 and 34 . The distributions of social class and marital state were broadly similar to those for the population of England and Wales overall as reported in the 1981 census. ${ }^{5}$ Not all subjects agreed to answer all the questions and hence the total number of responses for the reported items varied.

Table I also gives demographic information, when it was available, for the 86 men who were eligible for the study but were not interviewed and the 11 men excluded from analysis because of the presence of a third person. Comparison with the 480 men included showed that those who did not respond and those excluded were more likely to come from the south of England, to be in a lower (or unclassifiable) social class, and to be separated. Only social class showed a significant difference in distribution between those who were and were not interviewed $\left(\chi^{2}=9 \cdot 2, \mathrm{df}=3\right.$, $p<0.05)$. When the social class distribution of the 44 specific matched replacements for the 44 men who

TABLE I-Composition of men eligible for study by age at interview, area of residence, social class, marital state, and whether they were successfully interviewed

\begin{tabular}{|c|c|c|c|}
\hline & $\begin{array}{c}\text { No }(\%) \\
\text { successfully } \\
\text { interviewed }(n=480)\end{array}$ & $\begin{array}{c}\text { No (\%) } \\
\text { not interviewed } \\
(\mathrm{n}=97)^{\star}\end{array}$ & $\begin{array}{l}\% \text { Distribution in } \\
1981 \text { census (men } \\
\text { aged } 16-49)^{5}\end{array}$ \\
\hline \multicolumn{4}{|c|}{ Age at interview } \\
\hline $\begin{array}{l}15- \\
20- \\
30- \\
40-9\end{array}$ & $\begin{array}{c}33(7) \\
178(37) \\
200(42) \\
69(14)\end{array}$ & $\begin{array}{c}7(7) \\
33(34) \\
42(43) \\
15(16)\end{array}$ & \\
\hline \multicolumn{4}{|c|}{ Area of residencet } \\
\hline $\begin{array}{l}\text { South } \\
\text { Midlands } \\
\text { North } \\
\text { Wales }\end{array}$ & $\begin{array}{c}185(39) \\
93(19) \\
173(36) \\
29(6)\end{array}$ & $\begin{array}{c}43(44) \\
15(16) \\
36(37) \\
3(3)\end{array}$ & \\
\hline \multicolumn{4}{|c|}{ Social class } \\
\hline I & $\left.\begin{array}{r}39 \\
117\end{array}\right\}(33)$ & $6(14)$ & $27 \cdot 2$ \\
\hline $\begin{array}{l}\operatorname{IIIN} \\
\text { III } M\end{array}$ & $\left.\begin{array}{r}63 \\
161\end{array}\right\}(47)$ & $22(50)$ & $46 \cdot 4$ \\
\hline $\begin{array}{l}\text { IV } \\
\text { V }\end{array}$ & $\left.\begin{array}{l}59 \\
19\end{array}\right\}(16)$ & $12(27)$ & $21 \cdot 8$ \\
\hline Unclassified & $22(5)$ & $4(9)$ & $4 \cdot 6$ \\
\hline \multicolumn{4}{|c|}{ Marital state $\neq$} \\
\hline $\begin{array}{l}\text { Married } \\
\text { Divorced } \\
\text { Widowed } \\
\text { Separated } \\
\text { Single }\end{array}$ & $\begin{array}{c}294(61) \\
19(4) \\
3(1) \\
3(1) \\
161(34)\end{array}$ & $\begin{array}{c}34(54) \\
3(5) \\
4(6) \\
22(35)\end{array}$ & $\begin{array}{r}58 \cdot 5 \\
3 \cdot 4 \\
0 \cdot 3 \\
37 \cdot 9\end{array}$ \\
\hline
\end{tabular}

*Eighty six men not interviewed at all and 11 men not interviewed alone. Data on social class were available for only $\mathbf{4 4}$ men and on marital state for only 63 men.

only 63 men.
† South=North West Thames, North East Thames, South West Thames, South East Thames, Wessex, and South Western Regional Health Authorities; Midlands=Oxford Regional Health Authority; North= Yorkshire and North Western Regional Health Authorities; Wales= counties of Glamorgan and Gwent.

$\ddagger$ Civil state at interview, for comparison with census data, regardless of whether subject was cohabiting. were not interviewed and for whom we had social class data was examined it was found to be very similar to that for the overall sample of 480 .

\section{AGE AT FIRST INTERCOURSE}

For the 456 men who answered this question the median age at first sexual intercourse was 17 . Table II shows these data broken down by age at interview, social class, and area of residence. There was a significant difference among the age groups, age at first intercourse being lower in the more recent birth cohorts. Thus of the men in their 40 s when interviewed, $33 \%$ (21) had not had intercourse before the age of 20 compared with $2.1 \%$ (41) of the men in their $30 \mathrm{~s}$ and $20 \%$ (33) of the men in their $20 \mathrm{~s}$. Also, at least $67 \%(22)$ of the men in their teens at interview had experienced intercourse before the age of 18 compared with $47 \%$ (30) of the men in their 40 s. Twelve men were aged under 18 when interviewed, and thus the figure of $67 \%$ may be a slight underestimate.

There was also a significant difference among the social classes in age at first intercourse, men in higher social classes tending to have been older at first intercourse. There was no difference between the two categories of area of residence. When a Cox regression analysis was carried out fitting the two significant variables (age and class) the effect of social class remained significant $(p<0.01)$. The effect of age, however, was no longer significant $(p=0 \cdot 18)$, and thus some of the observed age difference might have been due to the differing social class composition of the age groups.

\section{NUMBER OF HETEROSEXUAL PARTNERS}

The men were asked to state the number of women with whom they had had sexual intercourse in two mutually exclusive categories. Firstly, they were asked about regular partners, defined as those "with whom you had sexual intercourse over a period of three months or longer at least once a week." Possible responses were $0,1,2-5,6-10$, and $\geqslant 11$. Secondly, they were asked about all their other (or casual) partners, defined as "all women with whom you ever had sexual intercourse but not those previously mentioned." Possible responses were 0, 1, 2-10, 11-24, and $\geqslant 25$. The term "other partners" was intended to include prostitutes, when relevant, but this was not made explicit in the interview.

Table III gives the frequency distributions for regular partners broken down by age at interview, social class, and region, and table IV gives data for casual partners. For both types of partner similar demographic trends were evident. There were significant differences in the number of partners among the different age groups. In part these resulted simply from the fact that with increasing age there had been

TABLE II-Age at first intercourse by age at interview, social class, and area of residence. Figures are numbers (percentages) of men

\begin{tabular}{|c|c|c|c|c|c|c|c|c|}
\hline & \multirow{2}{*}{$\begin{array}{l}\text { No of } \\
\text { men }\end{array}$} & \multicolumn{4}{|c|}{ Age at first intercourse } & \multirow[b]{2}{*}{ Never } & \multirow[b]{2}{*}{$x^{2 \star}$} & \multirow[b]{2}{*}{$\mathrm{p}$ Value } \\
\hline & & $<15$ & $15-17$ & 18-19 & $\geqslant 20$ & & & \\
\hline \multicolumn{4}{|l|}{$\begin{array}{l}\text { Age at interview: } \\
<20\end{array}$} & $3(9)$ & & 8 & \multirow{4}{*}{$5 \cdot 4$} & \multirow{4}{*}{$<0.05$} \\
\hline $20-$ & 168 & $14(8)$ & 77 (46) & $44(26)$ & $22(13)$ & $11(7)$ & & \\
\hline $30-$ & & 20 (11) & $83(44)$ & $47(25)$ & $35(18)$ & & & \\
\hline 40-49 & 64 & $4(6)$ & $26(41)$ & $13(20)$ & $21(33)$ & & & \\
\hline \multicolumn{9}{|l|}{ Social class: } \\
\hline I and II & 149 & $\begin{array}{l}8(5) \\
83(1)\end{array}$ & $\begin{array}{r}57(38) \\
\end{array}$ & $\begin{array}{l}36(24) \\
48(23)\end{array}$ & $42(28)$ & $\left.\begin{array}{r}6(4) \\
9(4)\end{array}\right\}$ & \multirow{2}{*}{10.5} & \multirow{2}{*}{$<0.01$} \\
\hline $\begin{array}{l}\text { III } \\
\text { IV and V }\end{array}$ & $\begin{array}{l}209 \\
76\end{array}$ & $\begin{array}{r}\begin{array}{r}23(11) \\
9(12)\end{array} \\
(10)\end{array}$ & $\begin{array}{r}102(49) \\
35(46)\end{array}$ & $\begin{array}{l}48(23) \\
19(25)\end{array}$ & $\begin{array}{l}27(13) \\
9(12)\end{array}$ & $\begin{array}{l}9(4) \\
4(5)\end{array}$ & & \\
\hline \multirow{3}{*}{$\begin{array}{l}\text { Area of residence: } \\
\text { South and midlands } \\
\text { North and Wales }\end{array}$} & & & & & & & \multirow{3}{*}{0.9} & \multirow{3}{*}{ NS } \\
\hline & 265 & $14(5)$ & $127(48)$ & $59(22)$ & $52(20)$ & $13(5)\}$ & & \\
\hline & 191 & $27(14)$ & $78(41)$ & $48(25)$ & $26(14)$ & $12(6)\}$ & & \\
\hline $\begin{array}{l}\text { Total } \\
95 \% \text { Confidence interval of } \%\end{array}$ & 456 & $\begin{array}{c}41(9) \\
7.7 \text { to } 10.3\end{array}$ & $\begin{array}{c}205(45) \\
42 \cdot 6 \text { to } 47 \cdot 3\end{array}$ & $\begin{array}{c}107(24) \\
21.5 \text { to } 25.5\end{array}$ & $\begin{array}{c}78(17) \\
15 \cdot 3 \text { to } 18 \cdot 9\end{array}$ & $\begin{array}{l}25(6) \\
4 \cdot 4 \text { to } 6 \cdot 6\end{array}$ & & \\
\hline
\end{tabular}

${ }^{\star}$ Log rank test for trend for age at interview and social class and for homogeneity for area of residence. 


\begin{tabular}{|c|c|c|c|c|c|c|c|c|c|}
\hline & \multirow{2}{*}{$\begin{array}{l}\text { No of } \\
\text { men }\end{array}$} & \multicolumn{5}{|c|}{ No of regular partners } & \multirow[b]{2}{*}{$\chi^{2}$} & \multirow[b]{2}{*}{$\mathrm{p}$ Value } & \multirow{2}{*}{$\begin{array}{l}\mathrm{p} \text { Value } \\
\text { for } \\
\text { trend } \dagger\end{array}$} \\
\hline & & 0 & 1 & $2-5$ & $6-10$ & $\geqslant 11$ & & & \\
\hline $\begin{array}{l}\text { Age at interview: } \\
15- \\
20- \\
30- \\
40-49\end{array}$ & $\begin{array}{r}33 \\
178 \\
200 \\
69\end{array}$ & $\begin{array}{l}11(33) \\
25(14) \\
10(5)\end{array}$ & $\begin{array}{r}7(21) \\
59(33) \\
75(38) \\
49(71)\end{array}$ & $\begin{array}{l}14(42) \\
85(48) \\
85(43) \\
16(23)\end{array}$ & $\begin{array}{r}1(3) \\
7(4) \\
17(9) \\
3(4)\end{array}$ & $\left.\begin{array}{r}2(1) \\
13(7) \\
1(2)\end{array}\right\}$ & $28 \cdot 3$ & $<0.001$ & $<0.01$ \\
\hline $\begin{array}{l}\text { Social class: } \\
\text { I and II } \\
\text { III } \\
\text { IV and V }\end{array}$ & $\begin{array}{r}156 \\
224 \\
78\end{array}$ & $\begin{array}{l}12(8) \\
12(5) \\
11(14)\end{array}$ & $\begin{array}{l}64(41) \\
99(44) \\
24(31)\end{array}$ & $\begin{array}{l}60(39) \\
98(44) \\
35(45)\end{array}$ & $\begin{array}{r}13(8) \\
9(4) \\
5(6)\end{array}$ & $\left.\begin{array}{l}7(5) \\
6(3) \\
3(4)\end{array}\right\}$ & $4 \cdot 9$ & NS & NS \\
\hline $\begin{array}{l}\text { Area of residence: } \\
\text { South and midlands } \\
\text { North and Wales }\end{array}$ & $\begin{array}{l}278 \\
202\end{array}$ & $\begin{array}{l}26(9) \\
20(10)\end{array}$ & $\begin{array}{r}119(43) \\
71(35)\end{array}$ & $\begin{array}{r}105(38) \\
.95(47)\end{array}$ & $\begin{array}{l}18(7) \\
10(5)\end{array}$ & $\left.\begin{array}{r}10(4) \\
6(3)\end{array}\right\}$ & $4 \cdot 2$ & NS & \\
\hline $\begin{array}{l}\text { Total } \\
95 \% \text { Confidence interval of \% }\end{array}$ & 480 & $\begin{array}{c}46(10) \\
8 \cdot 2 \text { to } 10 \cdot 1\end{array}$ & $\begin{array}{c}190(40) \\
37 \cdot 4 \text { to } 41 \cdot 8\end{array}$ & $\begin{array}{c}200(42) \\
39.4 \text { to } 43.9\end{array}$ & $\begin{array}{c}28(6) \\
4 \cdot 8 \text { to } 6.9\end{array}$ & $\begin{array}{c}16(3) \\
2 \cdot 5 \text { to } 4 \cdot 2\end{array}$ & & & \\
\hline
\end{tabular}

${ }^{*} \chi^{2}$ Tests are carried out after categories of no partner and one regular partner had been combined.

${ }^{*} \chi^{2}$ Tests are carried out after categories of no partner and one regular partner had been combined.
+ Trend tests carried out after men aged $15-29$ had been excluded; regression of age at interview (in individual years) on number of partners (in five categories).

TABLE IV -Number of casual partmers by age at interview, social class, and area of residence. Figures are numbers (percentages) of men

\begin{tabular}{|c|c|c|c|c|c|c|c|c|c|}
\hline & \multirow{2}{*}{$\begin{array}{l}\text { No of } \\
\text { men }\end{array}$} & \multicolumn{5}{|c|}{ No of casual partners } & \multirow[b]{2}{*}{$\chi^{2}$} & \multirow[b]{2}{*}{ p Value } & \multirow{2}{*}{$\begin{array}{l}\mathrm{p} \text { Value } \\
\text { for } \\
\text { trend } \dagger\end{array}$} \\
\hline & & 0 & 1 & $2-10$ & $11-24$ & $\geqslant 25$ & & & \\
\hline $\begin{array}{l}\text { Age at interview: } \\
15- \\
20- \\
30- \\
40-49\end{array}$ & $\begin{array}{r}33 \\
178 \\
199 \\
69\end{array}$ & $\begin{array}{l}14(42) \\
48(27) \\
55(28) \\
35(48)\end{array}$ & $\begin{array}{c}3(9) \\
20(11) \\
18(9) \\
4(6)\end{array}$ & $\begin{array}{l}13(39) \\
87(49) \\
81(41) \\
21(30)\end{array}$ & $\begin{array}{c}2(6) \\
16(9) \\
30(15) \\
8(12)\end{array}$ & $\left.\begin{array}{r}1(3) \\
7(4) \\
15(8) \\
3(4)\end{array}\right\}$ & $13 \cdot 4$ & $<0.05$ & $<0.05$ \\
\hline $\begin{array}{l}\text { Social class: } \\
\text { I and II } \\
\text { III } \\
\text { IV and V }\end{array}$ & $\begin{array}{r}155 \\
224 \\
78\end{array}$ & $\begin{array}{l}47(30) \\
73(33) \\
20(26)\end{array}$ & $\begin{array}{l}15(10) \\
18(8) \\
10(13)\end{array}$ & $\begin{array}{l}65(42) \\
92(41) \\
36(46)\end{array}$ & $\begin{array}{l}20(13) \\
28(13) \\
7(9)\end{array}$ & $\left.\begin{array}{r}8(5) \\
13(6) \\
5(6)\end{array}\right\}$ & $1 \cdot 3$ & NS & NS \\
\hline $\begin{array}{l}\text { Area of residence: } \\
\text { South and midlands } \\
\text { North and Wales }\end{array}$ & $\begin{array}{l}278 \\
201\end{array}$ & $\begin{array}{l}85(31) \\
65(32)\end{array}$ & $\begin{array}{l}32(12) \\
13(7)\end{array}$ & $\begin{array}{r}116(42) \\
86(43)\end{array}$ & $\begin{array}{l}29(10) \\
27(13)\end{array}$ & $\left.\begin{array}{l}16(6) \\
10(5)\end{array}\right\}$ & $1 \cdot 4$ & NS & \\
\hline $\begin{array}{l}\text { Total } \\
95 \% \text { Confidence interval of } \%\end{array}$ & 479 & $\begin{array}{c}150(31) \\
29 \cdot 2 \text { to } 33 \cdot 4\end{array}$ & $\begin{array}{l}45(9) \\
8 \cdot 1 \text { to } 10 \cdot 7\end{array}$ & $\begin{array}{l}202(42) \\
39 \cdot 9 \text { to } 44 \cdot 4\end{array}$ & $\begin{array}{c}56(12) \\
10 \cdot 2 \text { to } 13 \cdot 2\end{array}$ & $\begin{array}{l}26(5) \\
4.4 \text { to } 6.5\end{array}$ & & & \\
\hline
\end{tabular}

${ }^{\star} \chi^{2}$ Tests carried out after categories of no partner and one casual partner had been combined.

+ Trend tests carried out after men aged 15-29 had been excluded; regression of age at interview (in individual years) on number of partners (in five categories).

more opportunity to accumulate partners. There was, however, evidence of a change between men in their $40 \mathrm{~s}$ at interview and men in their $20 \mathrm{~s}$ and $30 \mathrm{~s}$. In general, men in the older age group had had fewer partners. Thus $71 \%(65.5$ to $76.5 \%)$ of men in their 40 s had had only a single regular partner compared with $38 \%(34.1$ to $40.9 \%)$ of men in their 30 s (another $5 \%$ (3.5 to $6.5 \%$ ) of men in their 30 s had had no regular partners). Among the older men $6 \%(3.1$ to $8 \cdot 7 \%)$ had had six or more regular partners and $16 \%(11.5$ to $20.3 \%) 11$ or more casual partners compared with $15 \%$ $(12 \cdot 5$ to $17 \cdot 5 \%)$ and $23 \%(19 \cdot 6$ to $25 \cdot 6 \%)$ respectively among men in their $30 \mathrm{~s}$.

To investigate further the trend with age regression analysis was carried out fitting age at interview (in individual years) to number of partners. This regression was confined to men aged over 30 and showed a significant negative relation with age for both regular $(\mathrm{p}<0.01)$ and casual $(\mathrm{p}<0.05)$ partners.

There were no discernible differences among the social classes or regions in the number of partners, nor did adding these factors as covariates to the regression models change the relation with age.

\section{HOMOSEXUAL PARTNERS}

In response to the question "Have you ever had homosexual intercourse?" eight of the 480 men $(1 \cdot 7 \%$, TABLE VI-Vasectomy by age at interview

\begin{tabular}{lc}
\hline Age & $\begin{array}{c}\text { No(\%) } \\
\text { with } \\
\text { vasectomy }\end{array}$ \\
\hline $25-$ & $1(1)$ \\
$30-$ & $12(10)$ \\
$35-$ & $10(13)$ \\
$40-$ & $12(27)$ \\
$45-9$ & $7(29)$ \\
\hline
\end{tabular}
casual homosexual partner and had never had a regul several heterosexual partners: three of the four had had a minimum of 12,13 , and 36 such partners. Of the four
TABLE $\mathrm{v}-$ Numbers of homosexual and heterosexual partners of eight men reporting homosexual intercourse

\begin{tabular}{|c|c|c|c|c|c|c|}
\hline \multirow{2}{*}{$\begin{array}{l}\text { Case } \\
\text { No }\end{array}$} & \multirow[b]{2}{*}{ Age } & \multirow{2}{*}{$\begin{array}{l}\text { Marital } \\
\text { state }\end{array}$} & \multicolumn{2}{|c|}{ Homosexual partners } & \multicolumn{2}{|c|}{ Heterosexual partner } \\
\hline & & & Regular & Casual & Regular & Casual \\
\hline 1 & 23 & Single & & 1 & $2-5$ & $2-10$ \\
\hline 2 & 43 & Married & & 1 & $\geqslant 11$ & $\geqslant 25$ \\
\hline 3 & 35 & Married & & 1 & $2-5$ & $11-24$ \\
\hline 4 & 26 & Single & & 1 & 1. & $11-24$ \\
\hline 5 & 39 & Married & 1 & & 1 & \\
\hline 6 & 25 & Single & 1 & $2-10$ & & \\
\hline 7 & 33 & Married & $2-5$ & $2-10$ & 1 & $11-24$ \\
\hline 8 & 29 & Single & $2-5$ & $\geqslant 25$ & & 1 \\
\hline
\end{tabular}

men who had had one or more regular homosexual partners, one reported never having had a heterosexual partner and two had had only one such partner. Only one respondent reported having had numerous heterosexual and homosexual partners, and one reported more than 25 casual homosexual partners. Four of the eight were married at the time of interview; two of them had had only one casual homosexual partner and two had had at least one regular partner.

\section{HISTORY OF SEXUALLY TRANSMITTED DISEASE}

Twenty nine of the 480 men $(6 \cdot 0 \%, 5 \cdot 0$ to $7 \cdot 1 \%)$ reported that they had had a sexually transmitted disease at least once, and 12 reported more than one episode. Twelve men specified at least one infection with gonorrhoea, 14 men had a history of non-specific urethritis, and four men had had genital herpes. One of the eight men who had had homosexual intercourse reported a history of sexually transmitted disease.

\section{VASECTOMY}

Forty two men $(8 \cdot 8 \%, 7 \cdot 5$ to $10 \cdot 0 \%)$ had had a vasectomy; table VI shows the proportion by age. The 
proportion rose in men aged over 40 . There were no appreciable differences in rates of vasectomy among the social classes but there did seem to be some regiona variation. Among men aged $30-49,28(17 \cdot 7 \%, 14 \cdot 7$ to $20.8 \%$ ) of those in the south and midlands had had vasectomies compared with $13(11 \cdot 7 \%, 8 \cdot 7$ to $14 \cdot 8 \%)$ of those in the north and Wales.

\section{INFERTILITY PROBLEMS}

Of the 318 men who stated that they had at some time tried to father a child, $62(19 \cdot 5 \%)$ reported a period of six months or longer when they had attempted to do so and failed. Fifty five of these 62 had eventually had children. Only two of the 62 men had been medically diagnosed as infertile.

\section{Discussion}

All studies of sexual behaviour are confronted with two major methodological difficulties - namely, bias in the selection of subjects and the reliability of the responses. Although both these issues are relevant to all studies based on interviews, they are particularly important with such a sensitive topic as sexual behaviour.

The extent to which men who are interviewed are representative of the general population depends on the criteria used for selecting the sample and whether non-responders have different characteristics from responders. The only qualifying factors for eligibility for this study were that the respondent should be white, mentally able to participate, and registered with a general practitioner. All of these qualifications impose limitations on the degree to which the results can be generalised. Although our study was also restricted to defined areas of England and Wales, these areas were geographically diverse and covered over a third of the entire population.

In terms of social class and marital state our respondents were similar to the national population (table I). Overall, therefore, the bias introduced in selecting the men eligible for the study was probably small and the results considerably more representative than those of other studies, which have focused on specific groups such as students or people attending sexually transmitted disease clinics. More of a problem is the $17 \%$ who did not respond. The men who could not be interviewed may have had different behaviour patterns from the respondents, especially as some of their demographic characteristics were slightly different (table I). There was, however, no prior indication that detailed questions on sexual history would be asked during the interview, and those men who gave reasons for not participating usually stated that they were too busy or did not like medical surveys.

We cannot evaluate how data from men who were not interviewed would have changed the results. Nor can we ascertain the truthfulness of responses from those participating in the study. The interviewers had invariably established a rapport with the men by the time that the questions on sexual history were asked, and they never reported any particular difficulty in asking these questions.

One way of attempting to validate the information obtained would be by comparing the results with those from other sources. The paucity of information about sexual behaviour in the general population, however, seriously limits the scope of such comparisons.

Two items presented in this paper for which crudely comparable routinely collected national information exists are rates of vasectomy and sexually transmitted disease. Rates of vasectomy are available from the Hospital In-Patient Enquiry for inpatients and outpatients. ${ }^{6}$ For the age group 15-44 (no finer age breakdown is available) the rate in 1985 was $4 \cdot 14$ per
1000. By applying this rate to the total person years at risk in this age group we calculated an expected number of $32 \cdot 1$ vasectomies in 480 men in this age group to compare with the 35 men reporting vasectomy in our study. If we allow for the additional vasectomies performed outside NHS hospitals the expected number is $41 \cdot 4$. Thus our results are compatible with routine statistics.

The reporting of sexually transmitted disease is perhaps a better indicator of the general validity of the responses in this study as these diseases are probably a topic about which respondents might be untruthful. Using reported annual rates of new cases of gonorrhoea in England and Wales, ${ }^{7}$ we would expect about $6.4 \%$ of our sample to have reported an episode. Also, we might expect a figure of perhaps double this for men reporting non-specific urethritis. ${ }^{7}$ Our rates of $2 \cdot 5 \%$ and $2.7 \%$ for gonorrhoea and non-specific urethritis suggest underreporting. National rates, however, relate to new diagnoses rather than individual people, some of whom will have had multiple episodes; $6.4 \%$ would thus be an overestimate of the proportion of our study population with at least one episode of gonorrhoea. Four men reported unknown types of sexually transmitted disease, some of which were probably gonorrhoea or non-specific urethritis. It is also possible that there is a small group of the male population, young, mobile, unemployed, and not registered with a general practitioner, who contribute disproportionately to the routine statistics. Taking these factors into consideration, it is unlikely that underreporting occurred by more than a factor of two.

For other items of information comparisons can be made to a limited extent with results from other specific studies carried out in the United Kingdom. In Schofield's studies 1873 teenagers were originally interviewed ${ }^{8}$ and 376 were reinterviewed seven years later. ${ }^{9}$ Fourteen per cent of his sample had had intercourse by the age of 16 , a further $20 \%$ at 16 or 17 , and a further $41 \%$ at $18-20$. Comparable figures from our study were $19 \%, 35 \%$, and $31 \%$ respectively for those in the age group 30 to 39 at interview (that is, those born at about the same time as Schofield's cohort). The results from our sample, therefore, show a tendency towards earlier first intercourse. In our study, however, age at first intercourse was more dependent on social class than birth cohort, and this should be taken into account when comparisons are made between different groups. A further complicating factor is that as a result of social mobility men questioned at different periods of their working lives may be assigned to a different social class.

A preliminary report of a telephone survey of 942 men aged 18-44 conducted in Edinburgh and Glasgow found that in the past five years half of the respondents had had only one partner and $7 \%$ had had more than 10 partners. ${ }^{10}$ The proportion of those reporting more than 10 partners declined steadily with age at interview from $11 \%$ of those aged under 22 to $2 \%$ of those aged 40-44. In our study we asked about lifetime number of partners, but in those aged 15-19 at interview these partners would have been within the past five years; in this age group $18 \%$ of our sample reported 11 or more partners (calculated by combining data on regular and casual partners). Our finding of an inverse relation between age at interview and total number of partners has also been reported in a recent study of women attending family planning clinics. ${ }^{11}$

Homosexual intercourse might be particularly underascertained, so possibly our figure of $1 \cdot 7 \%$ is below the true proportion. One way of validating our finding is to look at similar data for the patients with cancer of the testis for whom these men were matched controls. There was a very low rate of refusal among the patients (less than $1.5 \%$ ), and they had more 
motivation to report the truth. Fourteen of the 480 patients $(2 \cdot 9 \%)$ reported having had homosexual intercourse. Thus, unless homosexuality is associated with cancer of the testis (a hypothesis for which there is no evidence), we might conclude that if there was selection or underreporting in the control group 3\% would be a reasonable upper limit for the proportion of men who had had homosexual intercourse. This figure is in good agreement with McQueen et al's figure of $2 \cdot 8 \%$ of men reporting any kind of sexual contact with a person of the same sex in the past five years. ${ }^{10}$ It is also compatible with the lower end of a recent estimate by the Department of Health that 3-7\% of adult men are homosexual. ${ }^{12}$ This range was estimated from the results of a study in 1978 , which showed that $9 \%$ of men attending sexually transmitted disease clinics were homosexual,,$^{13}$ after allowance was made for the overrepresentation of homosexuals in the sample.

The original data from Kinsey et al based on surveys of the population of the United States in the 1940s are widely quoted but do not provide comparable estimates. ${ }^{14} 15$ Their methods were designed to allow study of rare types of behaviour by deliberately overrepresenting them in the sample. Thus frequently cited figures such as $10 \%$ of men being more or less exclusively homosexual cannot be regarded as applicable to the general population..$^{14} \mathrm{~A}$ recent analysis of data collected by the Kinsey Institute and the United States National Opinion Research Center on 1450 men in 1970, with more reliable sampling techniques, showed that $4.0 \%$ of these men reported having had a homosexual experience at least once and $1.9 \%$ reported having had such experiences either "occasionally" or "fairly often" after the age of $19 .{ }^{16}$ The authors suggest that these figures should be regarded as lower estimates of the true proportion, which they predict could be as high as $10 \cdot 6 \%$ and $6 \cdot 2 \%$ respectively. ${ }^{16}$ The question used in that study was about any homosexual experience that came to a sexual climax for either the respondent or his partner. If we allow for an increased positive response to this question compared with our question about homosexual intercourse we could estimate that the prevalence of homosexual behaviour was greater in the United States than in England and Wales but not more than double.

In general, and with the above provisos about accuracy and the effects of selection, our results show that the proportion of men having had homosexual intercourse is lower than is sometimes believed. Only eight out of 480 men reported homosexual intercourse, and of these only three had had more than one partner. There was just one man who had had more than 25 partners. Three of the four men with only one casual homosexual partner had had a large number of heterosexual partners, but of the other four men with at least one regular homosexual partner only one would properly be described as bisexual.

Homosexual intercourse was not specifically defined as anal intercourse (though this was the intention of the question), and thus the proportion of men who had practised anal intercourse could be even smaller than that recorded. In relation to AIDS, however, other homosexual activity besides anal intercourse is regarded as risky. Men participating in such activity but who have not participated in anal intercourse may therefore have answered "no" to the specific question about homosexual behaviour during our interview but might be recorded as positive in surveys with less restrictive questions.

The mode of transmission of AIDS through heterosexual intercourse is at present poorly understood, and whether a series of regular monogamous relationships carries a higher risk than a larger number of casual contacts is unclear. ${ }^{17}$ About $9 \%$ of the sample had had more than five regular heterosexual partners $(15 \%$ in the 30-39 age group) and $17 \%$ had had more than 10 casual partners (23\% in the $30-39$ age group). The men who had had a large number of regular partners also tended to have had a large number of casual partners, so, if we assume that the men in their teens or $20 \mathrm{~s}$ at interview will go on to have a similar number of partners to those currently in their 30 s, $23 \%$ of the male population might be defined as being at increased risk, of whom $15 \%$ might be at particular risk if regular relationships are important. Of course, these data alone cannot be used to predict the future risk of HIV infections or AIDS in heterosexual men. To do this it will be necessary to consider also other factors, such as use of condoms, not dealt with in this study.

The lack of a social class trend in rates of partnership is also relevant to the controversy over the aetiology of cervical cancer, another disease possibly related to sexual activity. Although a venereal component in the causation of this cancer has been reported, ${ }^{18}$ whether this also explains the strong social class gradient in the incidence of the disease, which is highest in women of lower social class, is unclear. ${ }^{19} \mathrm{~A}$ recent study of sexual behaviour among women showed that the number of sexual partners was not related to social class, ${ }^{20}$ but this leaves open the question of whether men's sexual behaviour could explain the effect of social class in cervical cancer. From our results this now seems unlikely to be the case. Young age at first intercourse has also been suggested as a risk factor for cervical cancer independent of number of partners. ${ }^{19}$ In both this study and that by Mant et al low social class was related to a lower age at first intercourse. ${ }^{20}$

Clearly it is not easy to study sexual behaviour in a truly representative sample of men because of problems of selection and, more importantly, a high rate of non-response among young men. A methodologically similar study among young women with the same interviewers had a rate of non-response of $11 \%$ that is, almost half that in the present study (C Chilvers, unpublished data). Despite repeated call backs and tracing of movers it can be extremely difficult to locate men in this age group and persuade them to be interviewed. It is unclear what other methods of contacting a sample of men would improve the response rate.

We thank the participants, interviewers, and regional organisers who took part in this study; Sheena Dawson, Krystina Baker, and Gwyneth Davey for clerical and computing help; Cynthia Bates and Sarah Jones for preparing the manuscript; and Sir Richard Doll for helpful comments. The Institute of Cancer Research receives support from the Cancer Research Campaign and the Medical Research Council.

\section{Appendix}

Principal investigators-D Forman, Oxford; C Chilvers, Sutton; R T D Oliver, department of medical oncology, The London Hospital Medical College, London; M C Pike, Imperial Cancer Research Fund epidemiology and clinical trials unit and department of preventive medicine, University of Southern California.

Regional collaborators-R A Cartwright, Imperial Cancer Research Fund genetic epidemiology laboratory, Leeds; P C Elwood, Medical Research Council epidemiology unit (South Wales); J Birch, department of epidemiology and social research, University of Manchester; C Tyrell, radiotherapy unit, Plymouth General Hospital.

1 Anderson RM. The epidemiology of HIV infection: variable incubation plus infectious periods and heterogenity in sexual activity. Foumal of the Royal Statistical Society, series A 1988;151:66-93.

2 Johnston AM. Social and behavioural aspects of the HIV epidemic-a review. fournal of the Royal Statistical Society, series A 1988;151:99-114.

3 Peto R, Pike MC, Armitage P, et al. Design and analysis of randomised clinical trials which require prolonged observation of each patient. 2 . Analysis and trials which require prolonged obser.
examples. Br f Cancer 1977;35:1-39.

4 Cox DR, Oakes D. Analysis of survival data. London: Chapman and Hall, 1984.

5 Office of Population Censuses and Surveys. Census 1981. National report, Great Britain. London: HMSO, 1983. (Parts 1 and 2.) 
6 Department of Health and Social Security and Office of Population Censuses and Surveys. Hospital in-patient enquiry for England 1985. London: HMSO, 1987. (Series MB4 No 27 .)

7 Department of Health and Social Security. On the state of the public health for the year 1986. London: HMSO, 1987.

8 Schofield M. The sexual behaviour of young people. London: Longman, 1965.

8 Schofield M. The sexual behaviour of young people. London. Longman, 1965.

9 Schold M. The sexual behaviour of young paluts. Lond All Lane, 1973. Provisional data from the RUHBC CATI survey. Research Unit in Health Provisional data from the RUHBC CATI survey. Research Unit in Heal and Behavioural Change. Edinburgh: April 1988. (RUHBC report No 2.)

11 United Kingdom Family Planning Research Network. Patterns of sexual behaviour among sexually experienced women attending family planning clinics in England, Scotland and Wales. British Jourmal of Family Planning 1988; 14:74-82.

12 Department of Health. Short-term prediction of HIV infection and AIDS in England and Wales. London: HMSO, 1988.

3 Belsey EM, Adler MW. Study of STD clinic attenders in England and Wales. British Joumal of Venereal Disease 1981;57:285-9.
14 Kinsey AC, Pomeroy WB, Martin CE. Sexual behaviour in the human male. Philadelphia: Saunders, 1949.

15 Gebhard PH, Johnson AB, eds. The Kinsey data: marginal tabulations of the 1938-1963 interviews conducted by the Institute for Sex Research. Philadelphia: Saunders, 1979.

16 Fay RE, Turner CF, Klassen AD, Gagnon JH. Prevalence and patterns of same gender sexual contact among men. Science 1989;243:338-48.

17 Peto J. AIDS and promiscuity. Lancet 1986;ii:979.

18 Buckley JD, Harris RWC, Doll R, Vessey MP, Williams PT. Case-control study of the husbands of women with dysplasia or carcinoma of the cervix uteri. Lancet 1981 ;ii:1010-5.

19 Rotkin ID. Etiology and epidemiology of cervical cancer. In: DallenbachHellwegg, ed. Current topics in pathology-cervical cancer. Berlin: SpringerVerlag, 1981:81-110.

20 Mant D, Vessey $M$, Loudon N. Social class differences in sexual behaviour and cervical cancer. Community Med 1988;10:52-6.

(Accepted 14 February 1989)

\title{
Effects of fibrinolytic inhibitors on mortality from upper gastrointestinal haemorrhage
}

\author{
David A Henry, Dianne L O’Connell
}

University of Newcastle, Newcastle, New South Wales 2308, Australia

David A Henry, FRCP, senior lecturer in clinical pharmacology, faculty of medicine

Dianne L O'Connell, PHD, lecturer in biostatistics, centre for clinical epidemiology and biostatistics

Correspondence to: $\mathrm{Dr}$ Henry.
Abstract

Objective-To see whether fibrinolytic inhibitors are of value when given to patients with upper gastrointestinal haemorrhage.

Design-Meta-analysis of six randomised double blind placebo controlled trials. Two methods used for obtaining an overall estimate of effect, including a random effects model incorporating any heterogeneity of outcome in the estimate of the overall treatment effect.

Setting-Inpatient care in hospitals in the United Kingdom, Sweden, and Australia.

Patients - 1267 Patients admitted to hospital with primary diagnosis of acute upper gastrointestinal haemorrhage. Five of the six trials included a high proportion of elderly patients. Most patients were bleeding from peptic ulcers in the stomach and duodenum (43-88\%) or gastric erosions (4-23\%). A variable proportion had a degree of clinical shock at entry.

Interventions-Tranexamic acid 3-6 g/day given intravenously for two or three days followed by 3-6 g/ day by mouth for a further three to five days (four trials) or 4-5-12 g/day by mouth for two to seven days (two trials).

End points-Frequency of recurrent haemorrhage, need for surgery, and death.

Main results-Treatment with tranexamic acid was associated with a $20-30 \%$ reduction in the rate of rebleeding, a $30-40 \%$ reduction in the need for surgery, and a $40 \%$ reduction (95\% confidence interval $10 \%$ to $60 \%$ ) in mortality.

Conclusions-Treatment with tranexamic acid may be of value to patients considered to be at risk of dying after an upper gastrointestinal haemorrhage.

haemorrhage have individually been too small to assess the effects on mortality.

This failure to test rigorously the candidate medical treatments for upper gastrointestinal haemorrhage is disappointing. Clinical trials are fairly straightforward, as most deaths occur within a week or two of the initial bleed and any benefits will be apparent after a short course of treatment. In the absence of definitive studies meta-analysis, which reviews critically the available clinical trials, assesses the homogeneity of any treatment effects, and pools the data to obtain an overall measure of benefit, may be valuable. ${ }^{4}$ Collins and Langman have reported a meta-analysis of randomised controlled trials of histamine $\mathrm{H}_{2}$ antagonists in upper gastrointestinal haemorrhage, which showed that treatment was associated with a modest reduction in the frequency of rebleeding, need for operation, and mortality and that benefit was most pronounced in patients bleeding from gastric ulcers.

The antifibrinolytic drug tranexamic acid was first tested in a randomised clinical trial for upper gastrointestinal haemorrhage in $1973 .^{\circ}$ Despite early claims of benefit, ${ }^{67}$ the drug does not appear to be widely used. For instance, the extensive survey of upper gastrointestinal haemorrhage published by the American Society for Gastrointestinal Endoscopy in 1982, which included a review of drug treatments employed by gastroenterologists in the United States, made no mention of fibrinolytic inhibitors. ${ }^{8}$ It was uncertainty about the role of fibrinolytic inhibitors that prompted this study.

The specific purpose of this study was to review and combine the results of all valid randomised controlled clinical trials in order to obtain an overall measure of the possible benefits of the use of fibrinolytic inhibitors in terms of reduced rates of rebleeding, emergency surgery, and death in patients admitted to hospital with a primary diagnosis of upper gastrointestinal haemorrhage.

Pharmacological treatments that have been tested in upper gastrointestinal haemorrhage, such as antacids, histamine $\mathrm{H}_{2}$ receptor antagonists, and fibrinolytic inhibitors, have theoretical appeal. Candidate drugs are cheap and comparatively safe and if they proved effective they could be given to most patients with this condition, including the many who are not looked after by specialists. The efficacy of drug treatment, however, has not been adequately evaluated. ${ }^{1}$ Survival is the most important measure of the success of management in upper gastrointestinal haemorrhage. In contrast with the extensive evaluation of $\beta$ adrenoceptor blockade or fibrinolysis after myocardial infarction, ${ }^{23}$ the trials of drug treatment in upper gastrointestinal

\section{Methods}

LIBRARY SEARCH

A Medline search (key words aminocaproic acids, tranexamic acid, haemorrhage, gastrointestinal) back to 1971 was supplemented by a manual search of the Index Medicus back to 1967 and a manual search of the Iowa Drug Information Service drug literature microfilm file back to 1977. Bibliographies of relevant articles, including published trials and general reviews of fibrinolytic inhibitors, were also used as sources of information. A manufacturer of fibrinolytic inhibitors 